American Journal of Pharmaceutical Education 2019; 83 (5) Article 6995.

\title{
BRIEF
}

\section{Impacting Student Self-Efficacy and Beliefs of Medication Therapy Management Through a Two-Week Elective}

\author{
Mariyem Naboulsi, PharmD, ${ }^{\mathrm{a}}$ Heather Hardin, PharmD, ${ }^{\mathrm{a}}$ Linda Behar-Horenstein, $\mathrm{PhD},{ }^{\mathrm{b}} \mathrm{Yu} \mathrm{Su}, \mathrm{PhD},{ }^{\mathrm{c}}$ \\ Richard Segal, $\mathrm{PhD}^{\mathrm{d}}$ \\ ${ }^{a}$ University of Florida College of Pharmacy, Gainesville, Florida \\ ${ }^{\mathrm{b}}$ University of Florida Colleges of Dentistry \& Education, Gainesville, Florida \\ ${ }^{c}$ Amplify, Brooklyn, New York \\ ${ }^{\mathrm{d}}$ University of Florida College of Pharmacy, Gainesville, Florida \\ Submitted February 3, 2018; accepted July 19, 2018; published June 2019.
}

Objective. To develop and introduce an intensive, two-week Foundations of Medication Therapy Management (MTM) elective course into the Doctor of Pharmacy curriculum, and to determine whether the course impacted students' self-confidence in their abilities to perform MTM services and future plans and beliefs about implementing MTM in practice.

Methods. The MTM course was an interactive learning environment where students performed actual comprehensive medication reviews within a real-world documentation platform. A 20-item, Likertscale survey was administered before and after the course to measure students' confidence in learned skills, future plans for using MTM, and beliefs about MTM.

Results. Students reported a significant improvement in 10 MTM-specific skill domains. There were significant changes in students' self-confidence in their ability to provide MTM services and in their beliefs about MTM-related services. Students reported overall improvement in self-perceived MTM specific skills. There was no significant change in students' willingness or plans to engage in MTMrelated practice in the future.

Conclusion. The findings showed that following participation in an MTM elective course, student pharmacists' perceived ability to deliver MTM care increased and their opinions about MTM services improved. Providing a brief MTM elective course that used first-person case studies may empower student pharmacists to confidently perform MTM services in subsequent courses and in their future practice.

Keywords: student pharmacists, attitudes or perceptions, pharmacy education coursework, pharmacist role

\section{INTRODUCTION}

Various pharmacy organizations, including pharmacy schools, have recognized that pharmacists may need additional instruction and experience in order to raise their awareness of the roles and responsibilities essential to providing patient-centered care. ${ }^{1,2}$ The practice area of medication therapy management (MTM) is not an exception to this recommendation. In addition to expanding practicing pharmacists' knowledge of MTM, educators believe that there should be greater emphasis on MTM education within the pharmacy school curriculum. ${ }^{3}$

Researchers suggest that the formation of professional identity is essential during the transition from student to professional and that the responsibility for fa-

Corresponding Author: Heather Hardin, Office of Experiential Programs, University of Florida College of Pharmacy, 8611 SW 92nd Ln., Gainesville, FL 32608. Tel: 352-359-5518. E-mail: pharmie@cox.net cilitating this transformation and ensuring that the future pharmacy workforce is adequately prepared to address patients' needs falls on pharmacy schools. The prospect of adding elective courses within an already full pharmacy curriculum has not been well received. ${ }^{4-6}$ The literature focuses on how coursework, in general, impacts student attitudes about pharmacists' roles within a patient-centered practice model. For example, one group concluded that providing support within a professional pharmacy degree program may better prepare graduates for entry into the healthcare workplace by establishing student competence, relatedness, and autonomy. ${ }^{4}$ The increased desire for advocates to "promote the pharmacy profession" describes a common objective between our study and these publications. Unlike other studies that have focused on traditional, non-accelerated classroom models, our study occurred in an active-learning environment that used a flipped classroom model. This innovative 


\section{American Journal of Pharmaceutical Education 2019; 83 (5) Article 6995.}

approach to learning creates strong ties between students and instructors and allows students to work together to gain a deeper understanding of the material. ${ }^{7}$

The specialty of MTM encompasses a range of health care services. These services include, but are not limited to, assessing and evaluating drug use and side effects, improving adherence, and managing disease states for all patients. Third-party payers, including certain Medicare Part D and Medicaid plans, reimburse pharmacists for providing medication reviews as part of MTM. ${ }^{8,9}$ In exploring what is known about MTM implementation within the pharmacy curriculum and student pharmacists' perception of MTM we found that there had not been any studies that directly assessed students' perception of MTM following an accelerated, two-week elective course. Additionally, there had been few studies that explored pharmacists' interests in MTM expansion to advance public health priorities. ${ }^{10}$ Based on a survey of a sample of Ohio pharmacists, Casserlie and colleagues identified potential barriers to pharmacists providing MTM services, including staffing concerns, time constraints, and lack of reimbursement. ${ }^{11}$ Developing solutions to these barriers is imperative and must occur early within the pharmacy curriculum so that student pharmacists are prepared to respond to the demands of an everchanging and challenging health care setting.

In 2015, the University of Florida College of Pharmacy (UFCOP) transitioned to a team-based learning curriculum, which involved "flipping" the classroom. As part of this new approach to learning, students would watch prerecorded lectures and read pertinent material prior to attending class. When they attended live classes, instructional time would be used for active learning. Students would be expected to comprehend background material before the live session and attend class prepared to use and apply that knowledge to patient cases.

The purpose of our study was to determine whether completing an intensive, two-week, active-learning elective course in Medication Therapy Management would change student pharmacists' attitudes regarding MTM and improve their self-confidence in their ability to perform MTM services. A secondary purpose was to determine if the course impacted students' beliefs regarding and plans to use MTM in their future practice.

\section{METHODS}

This study received approval from the university's institutional review board. The Foundations of Medication Therapy Management course was initially presented in the last few weeks of spring 2016 as a two-credit hour elective for second- and third-year student pharmacists. Students entered this course with minimal MTM knowl- edge and experience with related skills. This elective course was designed and implemented to provide students with a fundamental knowledge of MTM and to provide exposure to the many components involved in performing comprehensive medication reviews (CMRs). On the first day of the course, students completed a pre-course survey to assess their baseline self-efficacy in providing MTM services (reflective of the course objectives), their beliefs regarding MTM services, and their future plans to provide MTM services in their practice. Students completed the survey using the professional, encrypted version of Survey Monkey (San Mateo, CA). Students also were invited but not required to participate in the study by allowing their data to be included in the analysis.

Week one of the elective comprised 3.5 hours of active-learning sessions in class and 15.5 hours of online or individual study. During live sessions, group discussions were held and students were introduced to a computer platform used to perform MTM so that they could review and respond to patient cases. Independently, students were expected to complete supplemental readings and watch online lectures and complete online assessments. Online assessments covered typical MTM activities such as creating a patient medication action plan, a personal medication list, and a prescriber communication fax. During week two, students attended a 3-hour, liveclass session, completed 9.5 hours of online or individual study, and participated in an end-of-course survey that was identical to the pre-course survey. The second week concluded with a 2-hour final examination, in which students were required to complete a patient case. Total instructor contact hours for this course was 31.75 hours.

The researchers constructed a scale that included 20 items categorized into three subcategories, and used a 5 -point Likert scale $(1=$ strongly disagree, $5=$ strongly agree). The first subscale, consisting of 10 items, measured students' self-confidence in their ability to provide MTM services. The second subscale, consisting of three items, measured students' willingness to provide MTMrelated services in future practice. The third subscale, consisting of seven items, measured students' beliefs about MTM-related services. Demographic information collected included gender, age, and information about the student's prior experiences in pharmacy practice.

The researchers validated the survey instrument by asking for feedback from a survey expert, a research expert, and three MTM content experts. Based on their feedback, the survey instrument was revised and then piloted with two fourth-year student pharmacists who were completing a clinical APPE with one of the authors. After the student pharmacists completed the survey, the author conducted a detailed discussion of the survey items with the 


\section{American Journal of Pharmaceutical Education 2019; 83 (5) Article 6995.}

students and asked them to explain what they thought each question was asking and to state their reasons for the answers provided. Survey items were revised to reduce any confusion that the students had identified and to ensure that questions were worded in a way that would elicit the desired response.

Descriptive statistical analysis was performed using SPSS 23 (IBM, Armonk, NY). The a priori level of significance was set at $p<.05$. For the post hoc power analysis, Wilcoxon signed rank tests were employed to test for significant differences between pre- and post-test data for all items. The power to compare pre- and post-test means was 0.68 , which is less than the recommended 0.80 level but still considered acceptable. ${ }^{12}$

\section{RESULTS}

Twenty-six student pharmacists (16 female and 10 male students) completed both the pre- and post-course surveys. Because the course was offered during the first year of the new curriculum, only second-year student pharmacists were enrolled in the course. The entire cohort of students enrolled in the spring 2016 MTM course consented to participate in this pre- and post-test study. Table 1 shows the descriptive statistics and results for the preand post-test for all 26 MTM students. For subscale 1, students' self-confidence in their ability to provide MTM services, the mean scores on all the items were significantly different between pretest and posttest. That is, students' self-efficacy in their ability to perform MTM services significantly improved from pretest to posttest.

For subscale 2, willingness to engage in future MTM-related practice, no significant differences were found. For subscale 3, beliefs about MTM-related services, students' agreement that "Pharmacists should be the main providers of MTM services" and "Reimbursements should be increased for pharmacists providing

Table 1. Pre- and Post-Survey Results for Student Pharmacists Enrolled in a Two-Week Medication Therapy Management Elective Course $(\mathrm{N}=26)$

\begin{tabular}{|c|c|c|}
\hline Survey Item & $\begin{array}{l}\text { Pretest Mean } \\
\text { Response }\end{array}$ & $\begin{array}{l}\text { Posttest Mean } \\
\text { Response }\end{array}$ \\
\hline $\begin{array}{l}\text { Utilize my clinical knowledge to provide Medication Therapy Management (MTM) } \\
\text { services }\end{array}$ & 3.5 & $4.3^{\mathrm{a}}$ \\
\hline Reduce barriers that interfere with providing MTM services & 3.3 & $4.2^{\mathrm{a}}$ \\
\hline $\begin{array}{l}\text { Conduct a pre-analysis of a patient's MTM profile to recognize potential drug therapy } \\
\text { problems (DTPs) }\end{array}$ & 3.4 & $4.6^{\mathrm{a}}$ \\
\hline $\begin{array}{l}\text { Formulate appropriate MTM interview questions to assess the significance of potential } \\
\text { DTPs }\end{array}$ & 3.7 & $4.6^{\mathrm{a}}$ \\
\hline $\begin{array}{l}\text { Utilize appropriate communication skills when performing a comprehensive medication } \\
\text { review (CMR) }\end{array}$ & 4.0 & $4.6^{\mathrm{a}}$ \\
\hline $\begin{array}{l}\text { Create a patient-directed Medication Action Plan that guides the patient in self-addressing } \\
\text { their health and well-being }\end{array}$ & 3.3 & $4.6^{\mathrm{a}}$ \\
\hline $\begin{array}{l}\text { Complete a Personal Medication List that adheres to the Centers for Medicare and } \\
\text { Medicaid Services standardized format }\end{array}$ & 3.2 & $4.8^{\mathrm{a}}$ \\
\hline Prioritize clinically-significant DTPs after performing a CMR & 3.5 & $4.3^{\mathrm{a}}$ \\
\hline Devise a plan to address DTPs with the appropriate individual(s) & 3.5 & $4.5^{\mathrm{a}}$ \\
\hline $\begin{array}{l}\text { Write effective recommendations to healthcare providers that would likely resolve } \\
\text { DTP interventions }\end{array}$ & 3.3 & $4.4^{\mathrm{a}}$ \\
\hline Additional training on providing MTM services & 4.6 & 4.5 \\
\hline To acquire a position where I can practice MTM following graduation & 4.3 & $4.5^{\mathrm{a}}$ \\
\hline To implement MTM in future practice & 4.7 & 4.7 \\
\hline Pharmacists should be the main providers of MTM services & 4.7 & $4.9^{\mathrm{a}}$ \\
\hline Reimbursements should be increased for pharmacists providing MTM services ${ }^{a}$ & 4.6 & 4.9 \\
\hline MTM services can be effective via various methods of delivery & 4.7 & 4.8 \\
\hline MTM services improve patients' therapeutic outcomes & 4.8 & 4.9 \\
\hline MTM services decrease the likelihood of medication-related events & 4.7 & 4.8 \\
\hline MTM services will lead to legalized recognition of pharmacists as health care providers & 4.4 & 4.6 \\
\hline Pharmacy school curriculum is preparing me to provide MTM services & 4.3 & 4.6 \\
\hline
\end{tabular}

${ }^{a}$ Significant. This survey item refers to a skill or responsibility that significantly increased or improved at the end of the course compared to the beginning of the course 


\section{American Journal of Pharmaceutical Education 2019; 83 (5) Article 6995.}

MTM services," significantly increased from the pretest to the posttest.

\section{DISCUSSION}

The results of the survey suggest that implementing a two-week elective course in MTM significantly impacted student pharmacists' self-efficacy in their abilities and beliefs in providing patient-centered MTM services. Assessing this topic was important because all electives in the "flipped classroom" curriculum are now only two weeks in length. Other pharmacy schools can be encouraged in our findings that providing an accelerated course in MTM can impact students' beliefs about and self-efficacy in performing MTM services upon graduation.

Among the most significant changes resulting from student pharmacists' participation in the course were in subscale 1, item 1.6, "Create a patient-directed Medication Action Plan (MAP) that guides the patient in selfaddressing their health and well-being," and item 1.7, "Complete a personal medication list that adheres to the Centers for Medicare and Medicaid Services standardized format." These findings suggest that, after participating in the elective, student pharmacists had become more familiar with MTM specific terms and procedures and had gained confidence in performing these tasks. The students developed confidence in understanding all requirements to defining terms such as a Medication Action Plan (MAP), Drug Therapy Problem (DTP), Comprehensive Medication Review (CMR), or Personal Medication List (PML), and their roles in providing patient-centered care.

No significant changes were found in subscale 2, which assessed students' willingness to provide MTM services in the future. This may have been because students already held a highly favorable and clear perception of the extent that they would integrate MTM into their future career as they had self-selected themselves to take this elective course. Students also may have been aware that most community pharmacies require pharmacists to perform MTM as a part of their duties and were already willing to learn from the start.

As indicated by their ratings of subscale 3 items on the posttest, students felt more strongly than they had at the beginning of the course that pharmacists should be the main providers of MTM services and that reimbursements should be increased for pharmacists providing MTM services. However, the students who participated in this study already had highly favorable viewpoints on these issues before taking the course. Nonetheless, students' responses to this subscale may highlight their desire to promote the pharmacy profession, insist upon appropriate compensation, and advocate for additional roles for pharmacists in improving patient-centered health care.
In general, the findings demonstrate how an innovative, two-week MTM elective was successful in increasing students' abilities to complete MTM services. Doing so resulted in improvement in students' self-efficacy in providing MTM services and thus may encourage them to choose to complete additional MTM courses in the traditional classroom setting and through experiential learning. These findings supplement the current literature by emphasizing the importance of introducing MTM electives to the existing pharmacy curriculum. ${ }^{13-23}$ Previous authors who developed MTM educational experiences similar to our course have described analogous findings in terms of improving student pharmacists' self-efficacy and influencing their beliefs regarding the benefits and value of MTM services. ${ }^{13-24}$ Other experiences were offered through an MTM-based elective, laboratory-based courses, and practice experiences. However, none was an intensive, two-week MTM course.

Poole and colleagues and Hall and colleagues both designed an MTM course based on the American Pharmacists Association's (AphA's) MTM program at their respective colleges. Both studies evaluated student readiness, competence, and ability to provide MTM services through pre- and post-course surveys. Poole and colleagues focused on fourth-year students, whereas Hall and colleagues assessed self-efficacy across all four years of the PharmD program. Both studies concluded that pharmacy curricular MTM training without MTM interactive practice experience is not sufficient to address graduates' perceived deficiencies in this area. ${ }^{13,14}$ Our course effectively established that MTM practical interactive training within students' academic career may help close this gap and address these deficiencies. Our course was not based on APhA's MTM program, as we focused more on providing a hands-on, realistic experience in a community pharmacy and using actual MTM software to simulate the process of performing CMRs with patients. As student pharmacists are provided courses that promote high levels of self-efficacy in providing MTM services, they will likely become pharmacists that provide higher quality CMRs.

In two other MTM elective courses, Kuhn and colleagues and Eukel and colleagues used a survey instrument to assess students' perceived value of real-life, face-to-face MTM counseling sessions. Kuhn surveyed 18 students in a 15-week elective MTM course in which, on two separate occasions, students visited a local senior center that hosted low-income and homeless patients and provided supervised MTM services. Eukel evaluated 85 third-year student pharmacists performing CMRs using MTM on faculty members. Student training prior to conducting the faculty interviews included MTM lectures 


\section{American Journal of Pharmaceutical Education 2019; 83 (5) Article 6995.}

and practice cases provided through a pharmaceutical care laboratory course. Both studies evaluated students' abilities to perform key elements of MTM after instruction. Using a standardized rubric, course facilitators confirmed these findings. ${ }^{15,16}$ Compared to our study, which facilitated MTM discussions with simulated patient cases, we conclude that both face-to-face MTM services and simulated services assisted students in developing the skills and knowledge necessary to become proficient in MTM. The successful use of a flipped classroom and a two-week elective course offers new options for pharmacy schools that have limited resources and struggle with patient participation.

Several limitations should be considered when interpreting the results of our study. First, only one cohort of students at a single site participated in this study. The study investigators decided to publish this study after the initial course offering because of the significant results obtained and to supplement the available literature on MTM in the pharmacy curriculum. Future evaluations could address ways that this course can be improved to ensure increasingly better preparation for student pharmacists seeking to provide MTM services. Additionally, although the survey was a required course assignment, students were given the option to exclude their responses from the dataset. Students may have regarded the survey as a basic assignment and did not seriously evaluate their responses. This may have led to either highly positive or highly negative answers given simply to complete a requirement. To avoid the potential of this type of bias in future studies, students could be asked to provide their rationale for each survey response. Notably, none of the student chose to have his or her responses excluded from the analysis. The potential for students to overestimate their skills and talents is another limitation. For example, students tend to rate their abilities too high because of overconfidence. This may have affected the pre-course survey data. Thus, our results may have shown even more significant improvements in MTM skills if this bias could have been removed. Because the study only included second-year students, the findings are not generalizable to student pharmacists enrolled in other years of the PharmD curriculum. Another limitation is the authors' use of a marginally validated scale. As the tool is used in future offerings of the course, further effort will be made to determine its reliability and validity.

Future research should explore MTM-specific curricula and determine which learning activities correlate with students'perceived increased confidence and competence levels. Sustained data gathering with future cohorts may legitimize this methodology and help evaluate the impact of the elective course on deep learning and the use of authentic assignments in this population. This study failed to identify a significant difference in subscale 2. This finding may warrant that researchers further investigate the limited impact of further training and education on students' desire to provide MTM services even though they demonstrate a better understanding of the specialty. However, this finding may also reflect students' self-selection to participate in an MTM elective for the purpose of obtaining a position where MTM is practiced. Future retroactive studies should assess the effect that this course has on students' preparedness to develop and implement MTM services and evaluate the benefit of taking an accelerated two-week MTM elective course using students who ultimately become MTM providers.

\section{CONCLUSION}

A Foundations of Medication Therapy Management elective course delivered in a flipped classroom over an intensive, two-week period, positively contributed to student pharmacists' perceived confidence and competence in providing MTM services. Overall, students believed that pharmacists should be the main providers of MTM services and should receive compensation in this role. Students initially indicated a strong willingness to provide MTM services in their future role as pharmacist. However, the results do not suggest that by virtue of completing the course, students expressed interest in providing MTM services as future pharmacists. Pharmacy colleges who are looking to incorporate MTM into an already dense curriculum may want to consider incorporating a similar MTM elective to enhance student confidence in their future MTM experiences as a pharmacist. Future studies should consider reevaluating course content based on students' execution of most course objectives.

\section{REFERENCES}

1. BPS Board of Pharmacy Specialties. Board of Pharmacy Specialties. https://www.bpsweb.org. Accessed October 8, 2017. 2. Beck D, Baldwin J, Raehl C, Speedie M, Yanchick V, Kerr R. Roles of the pharmacy academy in informing consumers about the new American pharmacist. Am J Pharm Educ. 2011;75(10):S5. https://www.ncbi.nlm.nih.gov/pmc/articles/PMC3279024/pdf/ ajpe7510S5.pdf. Accessed October 10, 2017.

3. Accreditation Standards and Key Elements for the Professional Program in Pharmacy Leading to the Doctor of Pharmacy Degree ("Standards 2016"). Accreditation Council for Pharmacy Education. https://www.acpe-accredit.org/pdf/Standards2016FINAL.pdf.

Accessed October 8, 2017.

4. American Pharmacists Association (APhA) and the American Association of Colleges of Pharmacy (AACP). Call for Successful Practices in Medication Therapy Management in the Curricula by Colleges and Schools of Pharmacy. Washington (DC): American Pharmacists Association; 2011. https://www.aacp.org/sites/default/files/ MTMCurriculaCallForSuccessfulPracticesFullSubmissionReport1211.pdf. Accessed July 8, 2018. 


\section{American Journal of Pharmaceutical Education 2019; 83 (5) Article 6995.}

5. Noble C, O’Brien M, Coombes I, Shaw PN, Nissen L, Clavarino A. Becoming a pharmacist: students' perceptions of their curricular experience and professional identity formation. Curr Pharm Teach Learn. 2014;6:327-339. http://www.sciencedirect.com/science/ article/pii/S1877129714000203. Accessed October 10, 2017.

6. Frenk J, Chen L, Bhutta ZA, et al. Health professionals for a new century: transforming education to strengthen health systems in an interdependent world. Rev Peru Med Exp Salud Publica. 2010;376:1923-1958. http://www.thelancet.com/article/S01406736(10)61854-5/fulltext. Accessed October 10, 2017.

7. Jakobsen K, Knetemann M. Putting structure to flipped classrooms using team-based learning. IJTLHE. 2017;29(1):177-185.http://

files.eric.ed.gov/fulltext/EJ1135820.pdf. Accessed November 4, 2017. 8. Medication therapy management in pharmacy practice: core elements of an MTM service model, version 2.0. American Pharmacists Association and National Association of Chain Drug Stores Foundation. http://www.pharmacist.com/sites/default/files/ files/coreelementsofanmtmpractice.pdf. Accessed October 8, 2017. 9. Contract year 2016 medication therapy management program guidance and submission instructions. Center for Medicare U.S. Department of Health and Human Services. https://www.cms.gov/ Medicare/Prescription-Drug-Coverage/PrescriptionDrugCovContra/ Downloads/Memo-Contract-Year-2017-Medication-TherapyManagement-MTM-Program-Submission-v-040816.pdf. Accessed October 8, 2017.

10. Healthy People 2020. U.S. Department of Health and Human Service. http://www.healthypeople.gov. Accessed October 8, 2017.

11. Casserlie LM, Mager NAD. Pharmacists' perceptions of advancing public health priorities through medication therapy management. Pharm Pract. 2016;14(3):792. https://www.ncbi.nlm.nih.gov/pmc/articles/ PMC5061523/. Accessed October 12, 2017.

12. Cohen J. Statistical Power Analysis for the Behavioral Sciences. 2nd ed. Hillsdale, NY: Lawrence Erlbaum Associates; 1988.

13. Poole TM, Kodali L, Pace AC. Integrating mediation therapy management education into a core pharmacy curriculum. Am J Pharm Educ. 2016;80(4):Article 70. http://www.ajpe.org/doi/pdf/ 10.5688/ajpe80470. Accessed October 12, 2017.

14. Dahl JR, Hall AM. A scale to measure pharmacy students' self-efficacy in performing medication therapy management services. $\mathrm{Am}$ J Pharm Educ. 2013;77(9):Article 191. https://www.ncbi.nlm.nih.gov/ pmc/articles/PMC3831402/pdf/ajpe779191.pdf. Accessed October 12, 2017.

15. Kuhn C, Powell PH, Sterrett JJ. Elective course on medication therapy management services. Am J Pharm Educ. 2010;74(3):Article
40. http://www.ajpe.org/doi/full/10.5688/aj740340. Accessed October 10, 2017.

16. Eukel HN, Skoy ET, Frenzel JE. Provision of medication therapy management to university faculty and staff members by third-year pharmacy students. Am J Pharm Educ. 2010;74(10):Article 182. https:/www.ncbi.nlm.nih.gov/pmc/articles/PMC3058456/. Accessed October 10, 2017.

17. Donovan J, Cross J, Malloy M, et al. Experiences in teaching and learning: Incorporating the American Pharmacists Association's Delivering Medication Therapy Management services certificate program into an accelerated pharmacy curriculum. Curr Pharm Teach Learn. http://www.pharmacist.com/delivering-medicationtherapy-management-services-training-2017. Accessed October 10, 2017.

18. Gallimore CE, Thorpe JM, Trapskin K. Simulated medication therapy management activities in a pharmacotherapy laboratory course. Am J Pharm Educ. 2013;75(5):Article 95. https://www.ncbi.nlm.nih.gov/pmc/ articles/PMC3142971/. Accessed October 10, 2017.

19. Battaglia JN, Kieser MA, Bruskiewitz RH, Pitterle ME, Thorpe JM. An online virtual-patient program to teach pharmacists and pharmacy students how to provide diabetesspecific medication therapy management. Am J Pharm Educ. 2012;76(7):Article 131.

20. Tomko JR, Runyon AL, Lassila H. Student self-assessed medication therapy management skills resulting from caring for uninsured patients using team-based care. Curr Pharm Teach Learn. 2011;3(1):63-70. https://www.ncbi.nlm.nih.gov/pmc/articles/ PMC3448469/. Accessed October 12, 2017.

21. Childress BC, Bosler JN, Beck M. Improving student knowledge in medication management through an advanced pharmacy practice experience. Consult Pharm. 2013;28(6):390395. https://www.ncbi.nlm.nih.gov/pmc/articles/PMC3425925/. Accessed October 8, 2017.

22. Hata M, Klotz R, Sylvies R, et al. Medication therapy management services provided by student pharmacists. Am J Pharm Educ. 2012;76(3):Article 51. https://www.researchgate.net/ publication/224868577_Medication_Therapy_Management_ Services_Provided_by_Student_Pharmacists. Accessed October 10, 2017.

23. Agness CF, Huynh D, Brandt N. An introductory pharmacy practice experience based on a medication therapy management service model. Am J Pharm Educ 2011;75(5):Article 82. https:// www.ncbi.nlm.nih.gov/pmc/articles/PMC3142972/. Accessed October 10, 2017. 